LIAMES 2 - pp. 85-104, Primavera 2002

\author{
Mônica Veloso Borges ${ }^{1}$ \\ (Doutoranda IEL/UNICAMP)
}

\title{
O Estudo do Avá: Relato e Reflexões sobre a Análise de uma Língua Ameaçada de Extinção ${ }^{2}$
}

\begin{abstract}
This article aims at reporting and reflecting about the study of the Avá Language (Tupi-Guarani), that I have been developing since 2001. I discuss the problems, advancements and perspectives in the research of this endangered language. I present the first results of the analysis, concerning stress and possessive markers.
\end{abstract}

\section{INTRODUÇÃO}

Uma das preocupações dos lingüistas atualmente é o gradual desaparecimento de línguas e culturas, particularmente indígenas, em decorrência do decréscimo populacional de muitos povos (Adelaar, 2000; Crystal, 2000; Grenoble \& Whaley, 1998; Grosjean, 1982; Romaine, 1995). Estima-se que das seis mil línguas faladas no mundo hoje, pelo menos a metade se perderá dentro de um curtíssimo espaço de tempo.

Vários fatores são apontados como possíveis responsáveis pela extinção de línguas e culturas. Dentre eles, destacam-se o tamanho das comunidades, o isolamento de um

\footnotetext{
${ }^{1}$ Doutoranda em Lingüística Antropológica pela Unicamp, sob a orientação do Prof. Dr. Angel Humberto Corbera Mori. Professora Assistente II de Lingüística da Faculdade de Letras da UFG e membro da Divisão de Antropologia do MA. Agradeço a leitura e os comentários da pesquisadora Rosani Moreira Leitão, todos pertinentes e certamente acatados. Quaisquer erros e imperfeições são naturalmente de minha inteira responsabilidade.

${ }^{2}$ Uma versão preliminar deste trabalho foi apresentada na 54a Reunião Anual da SBPC, realizada na Universidade Federal de Goiás, em Goiânia, no período de 07 a 12 de julho de 2002, no Simpósio "O papel da Lingüística, da Sociolingüística e da Antropologia no Projeto Educacional e de Vitalização de língua e cultura Avá-Canoeiro", coordenado pela Profa. Dra. Silvia Lucia Bigonjal Braggio, sob o título de "Reflexões sobre a análise da língua Avá-Canoeiro". Este artigo é produto do Projeto Avá-Canoeiro. Uma proposta de educação: vitalização da língua e da cultura (Convênio FURNAS/UFG/ FUNAPE/FUNAI), financiado por FURNAS e executado pela equipe do Museu Antropológico (MA) da Universidade Federal de Goiás (UFG), sob a coordenação da Profa. Dra Silvia Braggio. Endereço eletrônico: mvborges@iel.unicamp.br
} 
grupo com relação a outros minoritários e majoritários, os casamentos interétnicos, as atitudes dos povos para com as línguas em contato, as políticas governamentais para as línguas e a educação das minorias étnicas, e o grau de similaridade entre as línguas majoritária e minoritária. Entretanto, Grosjean (1982) afirma que esses fatores são ambivalentes, visto que podem contribuir tanto para a perda quanto para a manutenção lingüísticas.

No Brasil, das línguas indígenas ainda não estudadas, cinqüenta por cento possuem uma quantidade reduzida de falantes, menos de cem, número que as coloca numa condição de iminente extinção (cf. Rodrigues, 1993). Com relação às línguas amazônicas, por exemplo, Rodrigues (2000) esclarece que as políticas de conquista da Amazônia reduziram consideravelmente a quantidade de populações indígenas que ali habitavam, e, como consequiência, o número de línguas. De acordo com o referido autor, há quinhentos anos, antes da chegada dos europeus, o contingente de línguas e de famílias lingüísticas era provavelmente maior, e grande parte delas era por certo mais populosa. Hoje, na Amazônia, a média de falantes por língua é de cem, aproximadamente.

A língua avá, objeto deste estudo, é classificada por Rodrigues (1986) como pertencente à Família Tupi-Guarani, do Tronco Tupi. É falada atualmente por um reduzido número de indígenas, cerca de quinze pessoas aldeadas, o que a faz ser considerada como língua "fortemente ameaçada de extinção"3. A maioria desses indígenas vive na aldeia Canoanã, na Ilha do Bananal, no Estado do Tocantins, desde 1973, quando foram contatados e instalados pela FUNAI junto ao povo javaé (Macro-Jê). Na aldeia próxima a Minaçu, localizada a oitenta quilômetros daquela cidade, vivem, numa área de cerca de 38.000 hectares, seis pessoas com as quais tenho trabalhado: Matxa ${ }^{4}$, a mais idosa do grupo; Nakwatxa, irmã de Matxa; Tuia, filha de Matxa; Iawi, o único homem adulto do grupo; o menino Trumak e a menina Putdjawa, filhos de Tuia e Iawi ${ }^{5}$. Esse grupo avá vive próximo ao município de Minaçu, desde 1983, quando foi contatado pela FUNAI ${ }^{6}$. Desse modo, os dois grupos avá habitam a grande distância uns dos outros e possuem pouco contato entre si.

O objetivo deste artigo é relatar e fazer algumas reflexões sobre o estudo da língua avá, que venho realizando desde 2001, na aldeia próxima a Minaçu. Antes, porém, apresentarei um breve histórico da trajetória do povo avá.

\footnotetext{
${ }^{3}$ De acordo com depoimentos de habitantes da região de Minaçu, há ainda outros Avá perambulando nas imediações, sem terem sido ainda contatados. Entretanto, as várias frentes de atração realizadas não conseguiram localizar outros indígenas avá.

${ }^{4}$ A ortografia dos nomes dos indígenas foi mantida como nos registros oficiais a que tive acesso, tais como documentos da FUNAI, porque a língua avá ainda não possui uma ortografia própria. Após as análises fonológica e morfofonológica, que estão sendo realizadas no momento, ela será elaborada.

De acordo com informações da Fundação Nacional de Saúde (FUNASA), que constam dos cartões de vacinação dos Avá, essas são as datas aproximadas de seus nascimentos: Matxa (1939), Nakwatxa (1944), Iawi (1961) e Tuia (1973). Já dos nascimentos dos meninos se tem certeza: Trumak nasceu em 1987, e Putdjawa em 1989.

Após quase duas décadas de fuga constante, os Avá adultos apresentaram-se a habitantes regionais, que imediatamente contataram a FUNAI. As crianças nasceram depois do contato. Em virtude da construção da Usina Hidrelétrica de Serra da Mesa ter atingido uma parte da área avá-canoeiro, foi firmado um acordo entre a FUNAI e FURNAS, responsável pela obra. Desse modo, FURNAS assumiu as responsabilidades referentes à manutenção financeira do grupo, bem como celebrou convênio com a FUNAI, a UFG, e a FUNAPE, para viabilizar o projeto de educação, mencionado mais adiante.
} 


\section{BREVE HISTÓRICO SOBRE O POVO AVÁ: DO ATAQUE E DA GUERRA, À TRAVESSURAE À "INVISIBILIDADE"}

Conforme nos explica Pedroso (1992; 1994), devido à carência de dados históricos, não se pode precisar o contingente populacional dos Avá, desde que foram inicialmente noticiados em Goiás. Segundo Toral (1984/1985), a estimativa mais antiga é a de 1824, quando foi apontada por Cunha Mattos (1979) a existência de trezentos "guerreiros". As primeiras informações de que dispomos a respeito desse povo datam do século XVIII, época em que frentes agropastoris estabeleceram-se em suas terras ${ }^{7}$. Na documentação histórica daquele século, os Avá foram freqüentemente denominados de "canoeiros", "índios de canoa" ou "Xavante de canoa" (cf. Pedroso, 1992; 1994; Toral, 1984/1985; Tosta, 1997) ${ }^{9}$.

Consta que de todos os indígenas que habitaram o Estado de Goiás, os Avá-Canoeiro estavam entre os mais temidos ${ }^{10}$, porque resistiram e reagiram bravamente tanto à dominação colonizadora que lhes era imposta quanto à política indigenista do período, que tinha por propósito a ocupação das terras dos povos indígenas e seu aliciamento em aldeamentos oficiais. Assim, em alguns momentos o lema era "ou subjugar os Canoeiros ou ser vencido por elles” (Brasil, 1924, apud Toral, 1984/1985: 298).

Desse modo, os Avá estavam sempre em constantes conflitos com o colonizador e eram considerados, inicialmente, "o perigo execrado" (Bertran, 1998: 24), tendo sido designados em livros, relatórios e documentos oficiais como "ferozes", "indomáveis", "temíveis", "arredios" e "avessos ao contato e ao processo catequético", embora detentores de grande inteligência e sagacidade. Segundo Pedroso et alii (1990), esses conflitos foram intensos, e duraram de 1770 até 1860.

Como afirma Pedroso (1992; 1994), a característica essencial dos Avá era a belicosidade, pois jamais aceitavam ser subjugados e, como estratégia, interrompiam a comunicação entre cidades e vilas, e atacavam e destruíam obstinadamente arraiais, povoados e fazendas, recusando-se a aceitar o contato pacífico e visando a permanecer autônomos e a manter afastado de suas terras “o inimigo explorador" (Toral, 1984/1985; Pedroso et alii, 1990). Este vinha avidamente em busca de mão-de-obra escrava indígena para o comércio açucareiro nordestino, e para o trabalho nas lavouras e nas minas.

${ }^{7}$ Foi também nesse século que ocorreram a ocupação e o povoamento de Goiás, devido ao descobrimento de minas de ouro (Palacin, 1994).

${ }^{8}$ A designação "canoeiros", comum no século XIX, é controversa. Conforme Pohl (1976: 213), ela provém do tipo de canoa que os Avá utilizavam. Para esse autor, elas "são troncos de árvores escavados, nos quais (os Avá) enfrentam audaciosa e habilmente até mesmo o caudaloso Maranhão".

${ }^{9}$ Segundo consta de vários estudos sobre a historiografia de Goiás, como os de Couto de Magalhães (1975), Cunha Mattos (1979) e Toral (1984/1985), os Avá seriam resultantes da miscigenação entre os índios Karijó, de São Paulo, e escravos fugidos dos quilombos. Pedroso (1992; 1994), no entanto, apresenta evidências e argumentos lingüísticos, antropológicos, históricos e biológicos que refutam o que chama de "Teoria da origem cafuza dos Avá-Canoeiro", embora não negue a existência de contato interétnico entre os Avá e negros. O termo "Xavante de canoa", em oposição a "Xavante de terra" (os Xavante-Akwẽ), comum no século XVIII, deve-se à crença de que os Avá pertenceriam à família dos Xavante, e que seriam, assim, índios Jê, e não Tupi.

${ }^{10}$ Conforme os estudos sobre a história de Goiás, os Avá-Canoeiro, os Kayapó e os Xavante foram os índios mais "ferozes" e temidos do Estado (cf. Rocha, 1998). 
A partir da década de 1860, foram intensas a dispersão e a movimentação dos Avá no Estado, quando foram registrados diversos ataques seus às bandeiras. A fim de coibi-los, e buscando fomentar a navegação no Rio Araguaia, formaram-se vários aldeamentos oficiais e criaram-se muitos presídios militares ${ }^{11}$, que, juntamente com as bandeiras punitivas e os destacamentos volantes, foram responsáveis pela quase total extinção dos Avá.

No entanto, após 1870, os Avá adotaram uma atitude distinta da descrita acima. Como nova estratégia de protesto contra a ocupação de seu território, e não mais possuindo meios e população suficientes para sustentar guerras e combates, começaram a fugir e a fazer "travessuras" pelos locais onde andavam, principalmente com animais, tais como amarrar porcos e bezerros, e depenar galinhas e outras aves. Assim, a trajetória desse povo vai da ameaça e do ataque, à travessura, quando passaram a ser tratados como "os índios brincalhões". Eis a razão pela qual sertanejos os denominavam, e ainda usualmente os denominam, de "invisíveis", porque, embora se soubesse de sua presença nas redondezas das fazendas e dos arraiais, por seus ruídos e "travessuras", nunca eram vistos, pois, como diz Pedroso (1992), faziam uso de certas "técnicas de ocultamento". Suspeita-se que ainda existam muitos outros Avá "invisíveis" nos sertões entre os Estados de Goiás e Tocantins (Bertran, 1998). Pedroso et alii (1990), por sua vez, falam ainda da existência de outros Avá inclusive no Estado de Minas Gerais, na fronteira com a Bahia. Por tudo isso, os Avá são habitualmente denominados de "O Povo Invisível”.

Em suma, as relações hostis entre os não-indígenas e os Avá, os freqüentes confrontos entre estes e os colonizadores, e os constantes massacres, chacinas e perseguições sofridos por esses indígenas trouxeram como conseqüências a dispersão desse povo num vasto território, sua fragmentação em pequenos grupos e, principalmente, a drástica redução de seu contingente populacional em nosso século (cf. Pedroso et alii, 1990; Toral, 1984/1985).

Passo agora a relatar o estudo que venho fazendo sobre a língua avá.

\section{OESTUDO DA LÍNGUA AVÁ: PROBLEMAS, AVANÇOS E PERSPECTIVAS}

O conhecimento que se tem acerca da língua avá resume-se quase exclusivamente a listas de itens lexicais, que foram coletadas por Couto de Magalhães, em 1863/1864 (publicada em 1957), Meech, em 1961, Harrison, em 1974, e Toral (s/d), todas bastante restritas. O estudo mais detalhado sobre a língua avá foi feito em 1996, e resultou na dissertação de mestrado de Paiva, na qual o autor apresentou um inventário dos fones e o quadro fonético, procedeu à identificação dos fonemas e elaborou as regras fonológicas que explicitam os processos fonológicos evidenciados no corpus observado e, a partir delas, confeccionou as matrizes fonética e fonológica. Há ainda um capítulo destinado à fonologia comparada e à inclusão do Avá na família Tupi-Guarani.

O estudo de Paiva (1996), porém, é bastante incipiente, já que abordou apenas a variedade da língua Avá falada em Canoanã, deixando de lado a variedade da aldeia de Minaçu. Ademais, como adverte o próprio autor, seu trabalho restringiu-se à fonologia do

${ }^{11}$ Esses presídios eram "um misto de estabelecimento penal, colônia agrícola e estabelecimento militar" (Rocha, 1998: 71). 
segmento, não envolvendo a constituição silábica e aspectos suprassegmentais. Some-se a isso o fato de o corpus pesquisado por Paiva resumir-se a somente quatro fitas cassete de sessenta minutos cada e uma fita de vídeo com uma hora de duração. A exigüidade de dados fez com que essa análise ficasse incompleta em muitos aspectos, tais como no estabelecimento do estatuto das vogais nasais, consideradas distintivas, portanto fonêmicas, a priori. Em suma, trabalhos aprofundados acerca da língua Avá são inexistentes, e uma análise fonológica e morfossintática minuciosa é tarefa de extrema urgência, dada a situação sociolingüística vivenciada por esse povo.

Mais urgente ainda é uma pesquisa a respeito da língua avá falada na aldeia de Minaçu, sobre a qual quase nada há documentado e analisado. Nessa perspectiva, o estudo que tenho feito é relevante para a documentação dessa língua, e para subsidiar um programa educacional que esteja em consonância com o contexto sociolingüístico desse povo, e que contribua para sua preservação física e lingüístico-cultural, porque, como afirma Craig (2000), os lingüistas possuem certas responsabilidades para com os povos indígenas. Uma delas relaciona-se ao desenvolvimento de projetos de educação bilíngüe e intercultural adequados à realidade vivenciada pelas diversas etnias. E esse compromisso é ainda maior quando se trata de línguas em perigo de extinção, como é o caso do Avá, cuja situação é preocupante, pois a população resume-se a cerca de quinze pessoas, distribuídas em duas aldeias bastante distantes uma da outra, e vivendo praticamente isoladas, sem contato entre si. Portanto, a língua e a cultura avá podem ser consideradas como extremamente ameaçadas de extinção, uma vez que o próprio povo Avá encontra-se ameaçado de extinção.

Meu estudo da língua avá tem por escopo contribuir para um maior conhecimento da Família Tupi-Guarani, em geral, e do Avá, especificamente. Também tem fornecido subsídios ao Projeto Avá-Canoeiro. Uma proposta de educação: vitalização da língua e da cultura (cf. Braggio, 2000). Desse modo, minha análise busca colaborar na criação de uma ortografia fundamentada nas particularidades da língua, e na elaboração de materiais didáticos que as contemplem, tais como livros de leitura sobre insetos, peixes e plantas, e histórias avá.

Até agora, minha pesquisa tem contemplado apenas o Avá falado em Minaçu, mas, posteriormente, será estudada também a variedade falada em Canoanã, com vistas a uma análise comparativa. Nessa aldeia encontram-se os outros Avá-Canoeiro, vivendo uma situação sociolingüística completamente distinta dos Avá de Minaçu, pois lá há, além dos falantes de Javaé e Avá, falantes de português e da língua Guarani (Tupi-Guarani) ${ }^{12}$.

A metodologia empregada nesse estudo, que ainda encontra-se em construção, e está sendo adotada também na pesquisa etnográfica com o grupo, é bem variada, e baseia-se nos trabalhos de Samarin (1967), Kibrik (1977), Vaux \& Cooper (1999), Duranti (2000), Abbi (2001) e Newman \& Ratliff (2001) ${ }^{13}$. Os dados são, em sua maioria, obtidos em situações reais e informais de fala, como diálogos entre os mais idosos. A intenção é que a documentação da língua Avá seja a mais abrangente possível, abarcando um grande número de eventos comunicativos, tais como diálogos, relatos de experiências e de

\footnotetext{
${ }_{13}^{12}$ Conforme observações feitas por mim em viagem de campo à área Javaé em 1993.

${ }^{3}$ A pesquisa etnográfica está sob a responsabilidade da pesquisadora Rosani Moreira Leitão, do Museu Antropológico da UFG.
} 
acontecimentos vivenciados no dia-a-dia pelos Avá, variadas situações de interação discursiva entre eles, e a narração de histórias, mitos e músicas, como também a descrição de festas, danças e artesanatos de que os adultos ainda se recordem. Sigo, assim, as instruções de Himmelmann (1998), que afirma que, principalmente no caso de línguas ameaçadas de extinção, a documentação deve ser a mais abrangente possível, envolvendo não apenas dados que mostrem o sistema lingüístico, mas também diversas práticas e tradições lingüísticas da comunidade de fala pesquisada.

O artesanato dos Avá é basicamente utilitário, consistindo em arapucas, cestos, ninhos para galinhas e outras aves, costuras, cabaças, cachimbos de cerâmica e maracás de cabaça. Trumak e Putdjawa, principalmente Trumak, confeccionam ainda, com papel, madeira e sucatas, brinquedos, como aviões, máscaras, revólveres, chapéus e relógios. Segundo o estudo etnográfico, em desenvolvimento, os Avá possuem o ritual da cachimbação, ligado a um ritual de cura (pajelança), em que os adultos fumam seus cachimbos, tocam e cantam ao som de maracás (Leitão, 2002) ${ }^{14}$.

Essa metodologia de coleta e análise de diálogos e entrevistas já é usada em outros tipos de pesquisa, tais como com variedades do português falado (cf., por exemplo, Neves (1999)). Contudo, com línguas indígenas, a metodologia mais utilizada ainda é a elicitação. Em meu estudo, a coleta de dados está sendo feita tanto de maneira formal, com gravações e elicitações, quanto em momentos informais. Os dados elicitados referem-se ao léxico da língua, e têm-se restringido basicamente a substantivos concretos. Segundo Mithun (2001), a elicitação direta é bastante útil tanto na observação do inventário fonológico de uma língua quanto na coleta de léxico referente a numerais, plantas, animais, partes do corpo, termos de parentesco, elementos da natureza, e itens lexicais culturalmente significativos, tais como nomes relacionados a comidas, remédios, canções, danças, cerimônias, utensílios, relações genéticas e itens do vestuário. A referida autora esclarece que a elicitação direta é uma boa ferramenta para se coletar longas listas de itens lexicais básicos, mas uma proporção substancial do léxico só aparecerá na fala espontânea.

Foram gravadas dezesseis fitas cassete, de sessenta minutos cada, com Trumak e, principalmente, com Putdjawa, que adora me ensinar novos itens lexicais, e tem-se revelado uma excelente professora da língua. Na maioria das vezes, a gravação é feita com os dois juntos, e um vai acrescentando informações e corrigindo a fala do outro. Os meninos demonstram orgulho em me estarem ensinando sua língua, de modo especial quando afirmo que são meus professores de Avá. Acho que isso aponta para uma atitude positiva deles no tocante à sua língua materna. Por outro lado, Trumak e Putdjawa ficam visivelmente chateados e decepcionados quando esqueço ou erro algo que eles já me ensinaram, e que, portanto, eu já deveria saber. Aí dizem que não vou aprender, que o Avá é difícil mesmo, e que minha cabeça é fraca. Apesar de terem sido gravadas dezesseis fitas, poucos são os dados conseguidos. Normalmente, deixo o gravador ligado para tentar obter enunciados, diálogos e textos que contribuam com a pesquisa. Porém, muita fita é gasta e muito tempo é despendido às vezes para a obtenção de pouquíssimos dados proveitosos à análise lingüística.

\footnotetext{
${ }^{14}$ Os Avá gostam muito de fumo e o consideram como remédio. Por isso, estão sempre solicitando: "Mônica, quando você vier, traz remédio para mim?" Sabe-se que o fumo faz parte da vida míticoreligiosa dos grupos tupi (cf. Pedroso (1994)).
} 
Constam das gravações enunciados com verbos descritivos, construções genitivas e itens lexicais referentes a cores, árvores, parentesco, insetos, peixes e partes do corpo, que foram coletados a partir de questionários lexicais, e em momentos de descontração, como as caminhadas pelo mato, o descanso na rede à tardezinha, e a observação das fotos que tiramos nas visitas à aldeia.

Muitos itens lexicais não foram gravados, mas anotados em cadernos de campo, tanto a partir da escuta direta, em situações informais, como na hora das refeições, nos momentos em que contava ou lia histórias para eles, nas horas em que ouvíamos músicas, indígenas ou não ${ }^{15}$, nos intervalos ou durante as atividades de letramento (desenhos, leituras, jogos, recortes de jornais e revistas, trabalhos com massinhas de modelar coloridas etc.), no banho de rio e na lavagem de roupas e vasilhas, quanto a partir de livros sobre botânica, zoologia, insetos, anatomia humana, fotos de minha família e deles, revistas, como Avião Revue e Asas ${ }^{16}$, Isto é e Veja, jornais, como Porantim, postais de outros povos indígenas (Cinta-Larga, Kamaiurá, Kalapálo, Yawalapity, Yanomami e Karajá) e lápis de cor. Para as cores também foram utilizados desenhos, figuras e peças do vestuário. Figuras e desenhos eram mostrados, e Trumak e Putdjawa iam dizendo os nomes em sua língua.

Nunca consegui que as crianças me contassem histórias em Avá, pois dizem não conhecer nenhuma. Apenas obtive um pequeno relato de Trumak, falando de uma visita à cidade de Minaçu, com menos de dez enunciados. Todavia, ainda não compreendi bem se não me contam histórias porque não as conhecem mesmo, porque não podem contá-las devido à alguma restrição cultural, ou, ainda, se essa atitude mostra uma diminuição de sua habilidade em falar Avá. Foram gravados com Iawi itens lexicais referentes a partes do corpo, usando os mesmos livros de anatomia. E com Nakwatxa foi gravado um pequeno texto, sobre a onça, e um diálogo entre ela e Iawi sobre o cachorro que o caseiro Geraldo tinha na ocasião, que estava amarrado, e escapoliu. Foram gravados também alguns diálogos entre as mulheres adultas. Esse foi um grande avanço desde que comecei a trabalhar com eles. Iawi e Nakwatxa, que, no início não haviam concordado em gravar, e mostravam-se sempre arredios, posteriormente o fizeram de muito boa vontade. Esses itens lexicais, os enunciados, os diálogos, o relato de Trumak e o texto de Nakwatxa estão sendo transcritos com base nos símbolos e diacríticos do Alfabeto Fonético Internacional (IPA, 1999), e com a ajuda de Trumak e Putdjawa, que ouvem comigo as fitas.

A gravação com Iawi e Nakwatxa foi feita de uma maneira bem descontraída. Ele chegou para ver os meninos desenhando, e encontrou um atlas do corpo humano que havia sido levado justamente com esse objetivo (Anatomia Humana, 2001). Logo se encantou com as fotos e as cores, e começou a me indicar as partes do corpo, no meu e no seu, e a dizer seus nomes em Avá. Riu muito das fotos e comentou: "esse aqui está morto mesmo, não é? Morreu tudo. Está todo cortado". Foi aí que lhe perguntei se poderia gravar, ao que respondeu afirmativamente, demonstrando um certo orgulho, inclusive, por me estar ensinando sua língua. Nakwatxa, por sua vez, desenhou uma onça. Então, lhe

${ }^{15}$ Os Avá adoram músicas, de todos os gêneros. Dentre seus cantores favoritos estão Rio Negro e Solimões, e Marlui Miranda. Por essa razão, os CDs estão sempre presentes em nossas atividades de letramento e de coleta de dados etnográficos e lingüísticos (cf. Referências).

${ }^{16}$ Essas revistas são trabalhadas com Trumak, que adora aviões e assuntos a eles relacionados, para partirmos sempre de seus interesses, e, assim, motivá-lo melhor nas atividades de letramento 
pedi para que me contasse uma história que tivesse uma onça como personagem ou que contasse uma experiência com onça. Foi aí que descreveu, no gravador, alguns hábitos da onça e como ela é. Posteriormente Trumak, com uma certa dificuldade em compreender a fala de Nakwatxa, me ajudou a entender o que havia sido dito. O momento do desenho é bastante produtivo para a coleta de dados, especialmente com Nakwatxa, que fala o tempo todo em Avá, e pára só de vez em quando para me ensinar algo sobre o que está sendo representado, ou sobre a língua. Ela gosta muito de desenhar animais. Mas, na maior parte do tempo, só fala comigo em Avá, desconsiderando que sei falar exclusivamente alguns itens lexicais dessa língua.

O diálogo entre os dois foi gravado, porque deixei o gravador ligado perto deles, enquanto viam os livros e desenhavam. Após a gravação, tudo foi ouvido por eles. Expliquei-lhes como usarei aquele material em meu estudo da língua, e como ele poderá ajudar no aprendizado do Avá escrito, que já está sendo iniciado por eles. Demonstraram satisfação com isso, e divertiram-se, rindo bastante, ao ouvirem suas vozes gravadas. Já com os meninos, o trabalho tem fluído bem melhor. No entanto, com eles só foi possível gravar itens lexicais isolados referentes ao seu cotidiano na aldeia. Enunciados descontextualizados não foram obtidos; somente obtive enunciados em seu contexto de produção, como por exemplo, "eu estou tomando banho no rio" só foi conseguido quando de fato eu e os meninos estávamos dentro do rio tomando banho; "eu estou lavando roupa" só foi falado em Avá dentro do rio, ao lavarmos roupa. Dessa forma, a coleta de dados da língua demanda tempo e vivência com os Avá. Some-se a isso minha limitação como pesquisadora, que ainda não domino a língua avá.

Como naqueles momentos era impossível anotar o que me diziam, repeti os enunciados e mais tarde lhes pedi para falarem novamente, a fim de que eu pudesse anotar tudo. Em algumas ocasiões, eles mesmos faziam questão de que o gravador estivesse ligado. É assim que tenho realizado o estudo da língua, aproveitando todos os momentos possíveis, tentando criar situações propícias, e respeitando as particularidades de cada um do grupo e sua vontade de gravar ou não. Não há como ter pressa nessa atividade. Portanto, sei que o estudo da língua será lento e progressivo, o que demandará mais tempo do que o inicialmente esperado. E é aqui que se coloca um problema já apontado por outros pesquisadores, como Grinevald (1998) e Everett (2001).

É difícil descrever e analisar bem uma língua ameaçada de extinção num período tão curto de tempo, como é o do doutorado. Por um lado, há os compromissos acadêmicos, os prazos e as exigências do programa ao qual se está vinculado. Dificilmente quem nunca trabalhou com uma língua ameaçada de extinção compreende como ocorre esse processo de estudo, e, muitas vezes, a demora na coleta de dados é tomada como limitação ou inabilidade (quando não incompetência!) do pesquisador. Por outro, há a necessidade urgente de uma boa documentação e de um estudo abrangente sobre a língua ameaçada, inclusive para dar suporte a projetos de educação que visam a (re)vitalizar a língua e a cultura, como é o caso do Projeto Avá-Canoeiro. Há que se conciliar esses dois aspectos. Em minha pesquisa, noto que a tese será apenas o ponto de partida para o estudo do Avá, o início do trabalho, a apresentação do que já pode ser analisado e do que ainda necessitará de mais aprofundamento. Um conhecimento mais completo e minucioso da gramática avá demandará mais tempo e extrapolará o período institucional mencionado. 
Como os dados podem surgir a qualquer instante, e em qualquer situação sóciodiscursiva, tenho sempre comigo um caderninho de anotações. Os próprios meninos lembram-se de levá-lo, se o esqueço, quando vamos ao mato apanhar materiais, como algodão, urucum, pedrinhas e folhas, para as atividades de letramento, ou vamos simplesmente passear. Mostram-se entusiasmados e motivados em me ensinar Avá. Putdjawa está sempre me dizendo: "O nome daquele passarinho/daquela planta você ainda não sabe. Anota aí no seu caderninho!". Aliás, eles estão sempre dispostos e prontos a ensinar Avá a todos que solicitam: atualmente, estão ensinando os caseiros Geraldo e Magna, que já falam vários itens lexicais, e se mostram muito contentes por isso. Essa atitude positiva do casal com relação à língua avá também tem contribuído muito para que os meninos sintam orgulho de sua língua e prazer em usá-la no dia-a-dia. Iawi e Nakwatxa também expressam satisfação quando me vêem falando algo em Avá, como quando cheguei em sua casa cumprimentando a todos em Avá e quando falei alguns itens lexicais referentes ao tema roça, no momento em que ele contava sobre a plantação de arroz que estava sendo realizada na reserva. Por outro lado, demonstra decepção quando erro algo que já deveria saber. Enquanto falávamos sobre a roça, troquei o item lexical ['uj] "arroz" por ['zuj] "sapo". ${ }^{17}$ Inicialmente, ele riu muito da troca, e, em seguida, deu-me uma bronca, dizendo que preciso prestar mais atenção ao que me ensinam. Demonstra, ainda, orgulho ao saber que seus filhos são meus professores de língua Avá.

Análises sobre línguas da Família Tupi-Guarani, tais como Tapirapé, Asurini, Guarani, Mbyá, Wayampi e Kamaiurá, dentre outras (cf. Leite (1977, 1995), Almeida, Irmãzinhas de Jesus \& Paula (1983), Monserrat \& Irmãzinhas de Jesus (1998), Facó Soares (1979), GrannierRodrigues (1990); Guedes (1991); Martins (1996), Jensen (1989); e Seki (2000)), bem como estudos sobre outras línguas Tupi (cf. Ayrosa (1937), Lemos Barbosa (1955), Borella (2000)), muito têm contribuído para minha análise do Avá, no sentido de uma melhor compreensão da inclusão dessa língua no grupo das línguas pertencentes àquela Família, e as relações que se estabelecem entre o Avá e elas. Os dados dessas línguas, além de estarem sendo usados na análise do Avá, principalmente em comparações, têm contribuído na coleta tanto de itens lexicais quanto de enunciados. Eles vão sendo lidos como se fossem da língua avá, e os Avá vão dizendo se são ou não aceitáveis e gramaticais; se aqueles itens lexicais existem ou não, ou se há algum item lexical semelhante em sua língua. Estão sendo usados ainda, para a comparação, dados coletados por Paiva (1996). De acordo com Rodrigues (1984/1985), a língua avá pertence ao subconjunto IV da Família Tupi-Guarani, juntamente com o Tapirapé e o Asurini do Tocantins. Por essa razão, estou estudando essas línguas, para dar suporte à minha análise do Avá. Um fato interessante ocorreu durante o momento em que ouvíamos o Cd dos Guarani Ñande Reko Arandu. Iawi, muito atento, começou a cantarolar as letras junto com os cantores, e, em seguida, foi traduzindo algumas frases para mim: "ele está dizendo que a chuva está caindo. Está bonito". Nakwatxa também acompanha as letras, cantando junto. Eles gostam bastante desse CD. Isso mostra que existe um grau de inteligibilidade entre o Guarani e o Avá. Resta minha análise averiguar qual é.

\footnotetext{
${ }^{17}$ Apresento os exemplos em transcrição fonética, porque, como já foi dito, ainda não foi elaborada a ortografia para o Avá, e a análise fonológica está sendo realizada.
} 
Tenho passado mais tempo e trabalhado mais de perto somente com as duas crianças (que, em virtude das atividades de letramento, permanecem mais tempo onde fico hospedada), que falam quase que apenas o português, embora entendam o Avá (Putdjawa tem uma compreensão ainda melhor que Trumak). Por outro lado, tenho tentado coletar dados com Matxa, Nakwatxa e Tuia, praticamente monolíngües em Avá. Iawi fala as duas línguas, usando o português com as crianças, e o Avá com as mulheres. Por conseguinte, a coleta e a análise de dados buscam conciliar os pressupostos teórico-metodológicos da pesquisa bilíngüe com os da monolíngüe, assim como os de estudos sobre línguas ameaçadas de extinção (cf. Grosjean (1982), Seki (1984), Romaine (1995), Grenoble \& Whaley (1998), Himmelmann (1998), Crystal (2000) e Everett (2001)). Os adultos, além de morarem na casa construída por eles mesmos, no alto do morro ("a casa do Iawi”, como é tratada pelos meninos) $)^{18}$, longe da parte central da aldeia (onde estão localizadas a enfermaria (onde me hospedo), a garagem, uma casa dos Avá, construída pela FUNAI, e as casas do Geraldo e do Chefe do Posto), num local de acesso restrito e difícil, são inquietos e têm pouca paciência para gravações, pois, afinal, essa não é uma atividade comum à sua cultura, além de estarem quase sempre muito ocupados com seus afazeres, tais como coleta de lenha, frutos e alimentação para seus animais de estimação ${ }^{19}$, criados dentro da casa do alto. Matxa passa o tempo todo deitada em sua rede, devido a problemas de saúde, relacionados a visão e locomoção. Normalmente Iawi, Nakwatxa e Tuia descem à casa do Geraldo todos os dias ${ }^{20}$ para buscar gêneros alimentícios, velas, pilhas, e outros materiais de que necessitam, assim como para visitar Trumak e Putdjawa. Aproveitam também para pegar objetos e roupas em sua casa construída pela FUNAI. Sendo assim, permanecem lá por um curto período de tempo, insuficiente para a coleta de dados. E o tempo que passo com eles na casa do alto é também curto para a gravação de dados, e, normalmente, estou acompanhada de muita gente. É preciso ficar mais tempo com eles nessa casa.

\footnotetext{
${ }^{18}$ Ao que tudo indica, os meninos referem-se desse modo àquela casa provavelmente por não a sentirem como sua, por não se identificarem com aquele espaço físico-cultural. Sua casa parece ser a do centro da aldeia ou a do caseiro Geraldo, onde têm passado a maior parte do tempo, subindo para a casa do alto quase que somente aos finais de semana, quando Geraldo vai para Minaçu (Borges, 2002a). As crianças preferem a casa do centro da aldeia e os adultos, a do alto. Estes afirmam que a casa construída pela FUNAI ("a casa velha da FUNAI", como dizem), é quente ou fria demais, aberta ou fechada demais, enfim, estão sempre encontrando razões para não ficarem lá, e regressarem para sua casa do alto, aquela que sentem como verdadeiramente sua. De lá têm uma visão privilegiada da reserva, enxergando todas as estradas e entradas, além de estarem longe dos habitantes e visitantes nãoindígenas. É apenas quando se está lá no alto do morro que se entende a opção dos Avá pela casa de cima.

Os Avá adoram animais, e cada um possui os seus. Dentre eles encontram-se pombos, periquitos, papagaios, araras e rolinhas, quase todos aos casais, e presos pelos pés, por um cordão amarrado a objetos pesados, tais como pedaços de madeira e tijolo. Na parte exterior da casa há um cão e um potrinho. Há ainda um galinheiro.

${ }^{20}$ Uma das mulheres sempre fica cuidando de Matxa, que nunca é deixada sozinha. Assim, ou Iawi desce com Tuia ou com Nakwatxa, nunca com as duas.
} 
Como foi dito, o estudo da língua tem sido feito de uma maneira bem lenta, de forma a respeitar a situação social do grupo. Assim, ainda não foi possível gravar histórias antigas na língua avá com Matxa e Nakwatxa, nem com Iawi, pois eles ainda não se dispuseram. Acredito que com o tempo, e quando já estiverem mais familiarizados comigo, isso será possível. Foi um grande avanço gravar com Iawi partes do corpo humano e com Nakwatxa o pequeno texto sobre a onça. Esse trabalho foi feito, aproveitando-se uma situação que se construiu ${ }^{21}$ e a transcrição tem sido feita com a ajuda dos meninos, que apresentam um pouco de dificuldade na compreensão do conteúdo das falas em Avá.

Uma atitude que tenho adotado com freqüência é usar tudo que já sei sobre a língua, de modo especial enunciados, como sugerido em Everett (2001). Essa atitude tem-se mostrado relevante por dois motivos. Primeiramente, porque serve de estímulo para que os Avá continuem usando sua língua; e, em segundo lugar, para motivá-los a continuar me ensinando, já que esse uso certifica que tenho aprendido o que eles me têm ensinado. Lembro-me, por exemplo, da satisfação de Trumak e Putdjawa ao perceberem que eu conseguia entender pelo menos o tópico de uma conversação. Na penúltima viagem à reserva, fui visitar os adultos na "casa do Iawi". Lá presenciei um diálogo entre Tuia, Matxa e Nakwatxa, em que esta última relatava às outras que havia ido ao mato e até à parte central da aldeia procurando comida e insetos para seus animais de estimação. Não consegui entender tudo que ouvi, mas escutei tudo com a máxima atenção, anotando todos os itens lexicais e enunciados que já sabia e podia apreender das falas, tais como [i nnad3I]

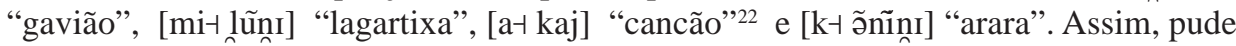
perceber que Nakwatxa ia falando da alimentação trazida para cada um de seus bichos, como lagartixas para seu gavião e para o de Matxa. Trumak, ao verificar que eu compreendia algo da conversa, ria e comentava: "você entendeu? Agora você entendeu, não é? Depois que eu ensinei".

A seguir apresento alguns aspectos da língua avá, referentes a acento e marcadores de posse.

\subsection{Aspectos da língua Avá: acento e marcadores de posse}

A análise preliminar do Avá realizada até agora refere-se basicamente à fonologia da língua e às suas construções genitivas. Quanto à fonologia, o aspecto mais interessante é que o acento não é predizível, e pode recair sobre a última, a penúltima ou a antepenúltima sílabas, diferentemente de outras línguas Tupi-Guarani, como o Kamaiurá (Seki, 2000), em que o acento recai sobre a última sílaba. Seguem-se exemplos.

${ }^{21}$ Todos os resultados da análise e descrição da língua avá encontram-se nos relatórios e trabalhos arquivados no acervo do projeto, no Museu Antropológico da UFG (cf. Borges, 2001a; 2001b; 2001c; 2001d; 2002a; 2002b; 2002c; 2002d; Borges \& Leitão, 2002).

O cancão é uma espécie de pássaro existente naquela região. 


\begin{tabular}{|c|c|c|}
\hline Kamaiurá & Avá & Tradução \\
\hline 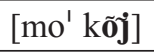 & ['mõkõj] & 'dois' \\
\hline [pe'tĩm] & ['petĩmõ] & 'tabaco' \\
\hline [hiwi'ra] & [hi'wira] & 'árvore’ \\
\hline [hauna't:si] & [ha'wat $\mathrm{i}$ i] & 'milho' \\
\hline [ipi'ra?] & [ipi'ra?] & 'peixe' \\
\hline
\end{tabular}

No que diz respeito à categoria de posse, pode-se afirmar que, na língua avá, assim como em outras línguas da família Tupi-Guarani, como o Wayampi (Jensen, 1989) e o Kamaiurá (Seki, 2000), encontram-se três tipos de nomes ${ }^{23}$ :

\section{1. os nomes inalienavelmente possuídos:}

- nessa classe incluem-se itens lexicais que expressam partes do corpo humano e de animais (ex: [i-' 3 iwi ${ }^{24}$ 'seu braço', [i-ri'piwa] 'sua perna'), e elementos eminentemente ligados ao homem ou ao animal (ex: [i-t ti'ska] 'xixi dele').

\section{2. os nomes alienavelmente possuíveis:}

- essa classe inclui utensílios domésticos e objetos culturais, como [tõ'petfĩnã] 'cesto', [gwe'gwe] 'flauta'.

\section{3. os nomes não-possuíveis:}

- essa classe inclui animais (ex: ['30كI] 'tartaruga'), plantas (ex: [mgi'tfi] 'buriti'), corpos celestes (ex: ['zai] 'estrela'), fenômenos da natureza (ex: ['tata] 'fogo'), elementos do ambiente (ex: [ũ'te] 'rio').

As marcas de pessoa nos nomes encontradas até agora foram:

- possuidor de $1^{\text {a }}$ pessoa singular $(1 \mathrm{sg})$ : t $\mathbf{t} \mathbf{i}-$

- possuidor de $2^{\mathrm{a}}$ pessoa singular $(2 \mathrm{sg})$ : ni-

- possuidor de $3^{\mathrm{a}}$ pessoa singular $(3 \mathrm{sg})$ : i-

A ordem é sempre o possuidor e, em seguida, o possuído, como nos seguintes exemplos:

${ }_{24}^{23}$ A marcação de posse no Avá é um dos critérios formais para se definir o que é um nome na língua.

${ }^{24}$ Os dados aparecem transcritos foneticamente, porque a análise fonológica da língua encontra-se em preparação. 
Borges: O Estudo do Avá: Relato e Reflexões sobre a AnÁlise de uma...

(1) ['tfi-po]

'minha mão'

1sg-mão

(2) ['ni-po]

'tua mão'

2sg-mão

(3) $\quad[$ 'i-po]

'mão dele (a)'

3sg-mão

(4) ['Mõnika 'i-po]

'mão da Mônica'

Mônica

3sg-mão

(5) ['t t i-kiwi $]$

'meu osso'

1 sg-osso

(6) ['ni-kwi]

'teu osso'

2sg-osso

(7) $\quad[$ 'i-kwi $]$

3 sg-osso

'osso dele (a)'

Quando não explicitei o possuidor, os Avá usaram ou o marcador de terceira pessoa singular /i-I, ou o item lexical [a'wa] 'gente', antecedendo os nomes equivalentes às partes do corpo, como nos exemplos (8), (9) e (10), que foram coletados com Iawi, quando folheava o Atlas do corpo humano.

(8) $\quad\left[a_{1} w a-' k i w i\right]$

gente - osso

(9) [a,wa-pia]

gente - fígado/entranhas

(10) $\quad[\mathrm{i}-\mathrm{pa}]$

3psg - fígado/entranhas 'osso de alguém, de gente, dele (a)'

'fígado de alguém, de gente, dele (a)'

'fígado dele (a)'

O dialeto Mbyá, da língua Guarani, possui um sistema de marcação de posse semelhante ao do Avá (ty-; ne-; i-), conforme se segue (cf. Guedes, 1991).

Mbyá Guarani

- pó

(12) ty-epó

1sg-mão 'mão'

'minha mão' 


$$
\text { i-pó 'mão dele' }
$$

3sg-mão

- raý

'filho'

(14) ne-ra?ý

2sg-filho

'teu filho'

O Avá possui marcadores de pessoa semelhantes a alguns do Tapirapé, em que aparecem xe-, ne- e i-, exemplificados abaixo (cf. Almeida, Irmãzinhas de Jesus \& Paula, 1983).

Tapirapé

xe-pinã

'meu anzol'

1 sg-anzol

(16) ne-xoro

2sg-boca

'tua boca'

(17) i-pyhã

'fígado dele'

3sg-fígado

Com os dados de que disponho no momento, ainda não é possível tecer maiores comentários sobre as construções genitivas em Avá. Não sei ainda, por exemplo, como se apresentam os prefixos relacionais nessa língua, quais são os marcadores de posse das pessoas do plural, e se há outros para as pessoas do singular.

\section{CONCLUSÃO}

Por tudo o que foi descrito, fica claro para mim que não será possível realizar o estudo aprofundado da língua avá, como é o objetivo, sem que esteja entre eles, principalmente com as mulheres, que falam com maior frequiência o Avá, mais tempo, andando pelo mato, tomando banho e lavando roupa no rio, enfim, vivendo com eles, especialmente na casa do alto. É imprescindível "gastar" tempo com os Avá, especialmente na "casa do Iawi”, ouvindo o máximo possível à língua e utilizando tudo que dela aprendi. Isso é importante, porque, além de ser uma oportunidade para que eles possam corrigir minha pronúncia e eventuais erros em meu aprendizado, serve para mostrar-lhes que seu trabalho como professores de sua língua não foi em vão. Acredito ser necessário aprender um pouco da língua, em seus diversos contextos de produção, para compreender o que os adultos falam, e poder, desse modo, obter os dados requeridos para a análise lingüística. Não há como estudar a língua apenas com o que coleto com as crianças. Creio que, para se trabalhar com uma língua ameaçada de extinção, e com um grupo tão reduzido de falantes, é necessário que o pesquisador tenha muita habilidade e sensibilidade para fazer de cada 
situação um momento adequado para o aprendizado da língua, e para não desrespeitar as peculiaridades do grupo e as características de cada um dos indígenas.

Tenho certeza de que não há como querer elicitar dados descontextualizados, pois os Avá recusam-se a pronunciar enunciados que estejam fora de seu contexto situacional, o que é bastante compreensível, afinal a língua não existe sem seu contexto sóciohistórico-cultural. Venho tentando obter, junto às mulheres adultas, enunciados com postais que representam cenas de cotidianos indígenas, como um índio kamaiurá pescando com arco e flecha, uma jovem dessa mesma etnia assando beiju, um índio yawalapiti fazendo um cesto e uma karajá amamentando seu filho, mas esta é uma tarefa que demanda tempo e paciência, e os resultados nem sempre são favoráveis. Já possuo muitos itens lexicais isolados, mas a língua não é composta apenas do léxico ${ }^{25}$. Assim sendo, no ano de 2003, pretendo viver um tempo com os Avá para aprender a falar um pouco da língua aváa ${ }^{26}$, e tentar documentá-la nos moldes sugeridos por Himmelmann (1998), com diversos tipos de textos: expositivos, procedurais, narrativos, exortativos, mitológicos e conversacionais. Por conseguinte, não há como o pesquisador controlar totalmente a coleta de dados, pois faz-se necessário aproveitar cada situação, cada acontecimento favorável e cada enunciado que surge espontaneamente.

Contudo, quero enfatizar aqui, que, a despeito do que acreditam muitos pesquisadores em línguas indígenas brasileiras, e de todos os problemas e situações adversos apontados neste artigo, creio ser absolutamente factível o trabalho de documentação, análise e descrição de uma língua ameaçada de ser extinta. Evidentemente, os obstáculos e limitações são vários e não há como querer negá-los. Porém, cada dado que se obtém e cada descoberta que se faz acerca da gramática da língua são uma grande conquista; é como conseguir ajuntar as peças de um enorme quebra-cabeça. Recordo-me da satisfação que senti ao conseguir chegar às marcas de possuidores de primeira, segunda e terceira pessoas do singular /t $\mathrm{ji}$-/ 'meu, minha', /ni/ 'teu, tua' e /i-/ 'seu, sua, dele, dela' no nome avá, mesmo com o paradigma ainda incompleto, a partir do emaranhado de dados que possuía. Afora isso, fica o sentimento de estar contribuindo para que não se perca mais uma das riquezas lingüísticas das cerca de cento e oitenta de que dispomos no Brasil, e de estar lutando para que o povo que utiliza essa língua não desapareça. Se a língua avá é importante para o desenvolvimento da ciência em geral, de maneira especial para a Lingüística, igualmente importantes são seus falantes.

\footnotetext{
${ }^{25}$ Não estou aqui desmerecendo o léxico, mas creio que um bom estudo da língua não deve a ele se restringir. A classificação do Avá foi feita com base exclusivamente em listas de itens lexicais. É necessário rever essa classificação, de posse de informações morfossintáticas, e assim confirmar ou reelaborar sua inclusão no grupo das línguas Tupi-Guarani.

${ }^{26}$ Isso ocorre também com outros lingüistas. Rogério Vicente Ferreira, doutorando em Lingüística Antropológica pela Unicamp, estuda o Matis, da família Pano, falado no Estado do Amazonas. Esse lingüista fala e compreende bem o Matis, sem o que, afirma, seu estudo morfossintático da língua seria inviabilizado. Os Matis, adultos e crianças, são praticamente monolíngües em Matis. Alguns poucos falam o português para se comunicarem com os não-indígenas, por exemplo, nas situações comerciais, e na cidade (Ferreira, em comunicação pessoal, 2002).
} 
Uma questão que muito me preocupa quanto ao futuro da língua avá é que, embora esta seja falada por todos os Avá, existe uma comunidade reduzida de falantes, e o não domínio dessa língua por parte dos não-indígenas com quem convivem na reserva (cerca de dez funcionários, entre caseiros, motoristas da Toyota e auxiliares do Posto Indígena) limita suas alternativas de uso do Avá, e estimula uma necessidade cada vez maior de emprego da língua portuguesa, o que pode provocar o desuso da língua Avá em várias situações comunicacionais, especialmente pelas duas crianças. Percebo que Trumak e Putdjawa usam somente o português entre si, e também com Tuia e Iawi. Já com Nakwatxa e Matxa, Putdjawa fala Avá, pois elas entendem pouco de português, e só falam com os dois meninos em Avá. Trumak, por sua vez, só usa o português, em todos os contextos e com todos os membros do grupo. Nunca o ouvi falar Avá com os adultos. Além disso, notam-se influências do português no Avá falado pelas crianças, tais como o contóide lateral palatal $[K]$, inexistente no sistema fonológico do Avá, sendo usado por Trumak e Putdjawa onde os adultos usam a aproximante palatal [j], como em ['waKoa] "guariba', que alterna com ['wajoa], estando, então, a primeira pronúncia restrita exclusivamente à fala das crianças.

Tuia às vezes conversa com os filhos em Avá, mas é o português que usa na maioria de suas interações verbais com eles, e às vezes até com Iawi. Este, por seu turno, fala com os filhos apenas em português. Trumak e Putdjawa, infelizmente, têm revelado, em alguns momentos, uma certa rejeição ao modo de vida tradicional de seus familiares, sendo fortemente seduzidos pelo modo de vida não-indígena, com o qual têm convivido cada dia mais de perto. Essa situação fica clara quando se visita com eles a "casa do Iawi". A maneira como tratam os adultos e como se comportam na casa aparentemente aponta para esse sentimento de rejeição. Aquele universo e aquela realidade parecem não lhes envolver.

É necessário lembrar que eu estava presente naquelas interações, e não sei o que ocorre quando os Avá estão sozinhos, em sua casa, sem a presença do não-indígena, mas, sem dúvida, o uso crescente do português na aldeia, por um número de pessoas maior do que a própria população do grupo é preocupante. Penso ser preciso que nós do projeto Avá-Canoeiro promovamos mais formas de incentivar o uso da língua avá na comunidade. Esta preocupação é extensiva a outros aspectos da cultura e à falta de condições propícias à realização das práticas culturais tradicionalmente desenvolvidas pelo povo Avá, tais como seu reduzido contingente populacional.

Acredito que o fato de eu estar estudando a língua avá e de outras pessoas, como o casal Magna e Geraldo, e sua filha Mikaella, quererem também aprendê-la, contribui um pouco para que ela possa continuar sendo usada pelo grupo. Essa nossa atitude positiva com respeito à língua e à cultura avá tem colaborado para que eles, especialmente os adultos, sintam orgulho de falarem Avá. Nessas situações, vejo-os motivados e alegres. Lembro-me da felicidade de Nakwatxa, ao me ouvir dizer [ka' wagu e' te] ("cavalo" + "gostoso") ("cavalo é gostoso"), quando íamos buscar sua égua no pasto, e brinquei com ela dizendo-lhe que iria comer o animal, pois sua carne é gostosa/saborosa, numa alusão a um episódio em que um cavalo que andava nas redondezas, quando os Avá ainda não haviam sido contatados e instalados naquele local, foi comido pelo grupo. Ela ria muito e me abraçava, dando explicações polidas, e falando com muita gentileza que eu não poderia fazer aquilo, porque aquela égua the 
pertencia, e porque o Pinotxe $\mathrm{e}^{27}$ ficaria bravo e brigaria muito comigo. Percebi que ela estava contente naquele momento por eu de certa forma fazer parte de seu universo e por saber falar algo em sua língua, além de itens lexicais apenas.

\section{REFERÊNCIAS BIBLIOGRÁFICAS}

1. CDs:

As mais conhecidas cantigas de roda para crianças. Turma Dó-Ré-Mi.

Echoes of Incas. USA: Earthtone Records, 1996.

Etnias (Kaiapó, Kamayurá, Fulni-ô, Pankararú, Bakairi, Kaiwá). Aldear. 2000.

Ihu - Todos os sons. Marlui Miranda. 1995.

2 Ihu-Kewere: Rezar. IV Centenário da Páscoa do Beato José de Anchieta. Marlui Miranda. 1997.

Imagens - Aurio Corrá. Alquimusic Echos. Série Alquimia. Vol. 1, 1995.

Ñande Reko Arandu. Memória Viva Guarani. World Music. 2000.

Paisagens. Ivan Vilela. Viola Caipira. 1998.

Sacred Spirit. Chants and Dances of the Native Americans. USA: Virgin Records Ltd., 1994.

Txai. Milton Nascimento. Sony Music.

Villa-Lobos para crianças. Seleção do Guia Prático. Coro Infantil do Teatro Municipal do Rio de Janeiro. Acervo Funarte-Música Brasileira, 1987.

Xokó. Aldeia Indígena São Pedro. Secretaria de Estado da Cultura/Governo de Sergipe/ FNDE-Núcleo de Educação Indígena, 1996.

\section{OUTROS}

ABBI, A. (2001). A manual of linguistic field work and structures of indian languages. LINCOM EUROPA.

ADELAAR, W. F. H. (2000). "La diversidad lingüística y la extinción de las lenguas". In QUEIXALÓS, F. \& RENAULT-LESCURE, O. (orgs.). As línguas amazônicas hoje. São Paulo: Instituto Socioambiental (ISA)/IRD/MPEG, 29-36 pp.

ALMEIDA, A. (1983). IRMÃZINHAS DE JESUS \& PAULA, L. G. A língua Tapirapé. Rio de Janeiro: Xerox do Brasil.

Anatomia Humana. (2001). Série Atlas visuais. São Paulo: Ática.

${ }^{27}$ Pinotxe é a maneira carinhosa como os Avá referem-se ao Valter, chefe do Posto Indígena. Surgiu com as crianças, e possui algumas derivações, como Pinotxinha. 
AYROSA, P. (1937). Os "nomes das partes do corpo humano pella língua do Brasil" de Pero de Castilho. Texto Tupi-Português e Português-Tupi do século XVII. São Paulo: Empresa Gráfica da Revista dos Tribunais.

BERTRAN, P. (1998). História de Niquelândia. Do distrito de Tocantins ao Lago de Serra da Mesa. $2^{a}$ ed. Brasília: Verano.

BRAGGiO, S. L. B. (2000). Projeto Avá-Canoeiro. Uma proposta de educação: vitalização da língua e da cultura. Goiânia: UFG/FL/DELL (mimeo).

BORELLA, C. C. (2000). Aspectos morfossintáticos da língua Aweti (Tupi). Campinas: UNICAMP. (Dissertação de Mestrado).

BORGES, M. V. (2001a). Relatório das atividades realizadas na Área Avá-Canoeiro $n^{\circ}$ 1. Goiânia: UFG/MA. (mimeo).

.(2001b). Relatório das atividades realizadas na Área Avá-Canoeiro $n^{\circ}$ 2. Goiânia: UFG/MA. (mimeo).

.(2001c). Relatório das atividades realizadas na Área Avá-Canoeiro n 3. Goiânia: UFG/MA (mimeo).

.(2001d). Notas sobre o Projeto Avá-Canoeiro: língua e educação. Comunicação apresentada no XLIX Seminário do Grupo de Estudos Lingüísticos do Estado de São Paulo (GEL). Marília: Fundação Eurípedes Soares da Rocha. 24 a 26 de maio de 2001. (mimeo) .(2202a). Relatório das atividades realizadas na Área Avá-Canoeiro $n^{\circ} 4$. Goiânia: UFG/MA. (mimeo).

.(2002b). A expressão de posse na língua Avá-Canoeiro (Tupi-Guarani): aspectos preliminares. Comunicação apresentada na Mesa "Construções Genitivas em Línguas Indígenas Brasileiras", no L Seminário do GEL. São Paulo, 23 a 25 de maio de 2002. (mimeo).

.(2002c). Notas preliminares sobre a fonologia segmental do Avá-Canoeiro (Tupi-Guarani). Comunicação apresentada no L Seminário do GEL. São Paulo, 23 a 25 de maio de 2002. (mimeo). .(2002d). Reflexões sobre a análise da língua Avá-Canoeiro. Comunicação apresentada no Simpósio "O papel da Lingüística, da Sociolingüística e da Antropologia no projeto educacional e de vitalização da língua e da cultura Avá-Canoeiro", na 54ª Reunião Anual da SBPC (Sociedade Brasileira para o Progresso da Ciência). Goiânia, 07 a 12 de julho de 2002. (mimeo)

BORGES, M. V. \& LEITÃO, R. M. (2002). Relatório trimestral das atividades realizadas na Área AváCanoeiro. Goiânia: UFG/MA. (mimeo).

COUtO DE MAGAlHÃES, J. V. (1975). Viagem ao Araguaia. 6a ed. São Paulo: Companhia Editora Nacional, 1975 (Coleção Brasiliana $n^{\circ}$ 28). (1 $1^{\text {a }}$ ed. de 1957).

CRAIG, C. G. (2000). "Los lingüistas frente a las lenguas indígenas". In QUEIXALÓS, F. \& RENAULTLESCURE, O. (orgs.). As línguas amazônicas hoje. São Paulo: Instituto Socioambiental (ISA)/ IRD/MPEG, pp. 37-52.

CRYSTAL, D. (2000). Language Death. Cambridge: Cambridge University Press.

CUNHA MATTOS, R. J. (1979). Chorographia historica da provincia de Goyaz (1824). Goiânia: Convênio SUDECO/Governo do Estado de Goiás.

DURANTI, A. (2000). Linguistic Anthropology. Cambridge: Cambridge University Press.

EVERETT, D. (2001). "Monolingual field research".In NEWMAN, P. \& RATLIFF, M. Linguistic Fieldwork. Cambridge: Cambridge University Press, pp. 165-188.

FACÓ SOARES, M. (1979). A perda da nasalidade e outras mutações vocálicas em Kokáma, Asurini e Guajajára. Rio de Janeiro: UFRJ. (Dissertação de Mestrado). 
GRANNIER-RODRIGUES, D. M. (1990). Fonologia do Guarani Antigo. Campinas: Editora da Unicamp. (Série Línguas Indígenas).

GRENOBLE, L. A. \& WHALEY, L. I. (1998). (eds.) Endangered languages. Language loss and community response (currents issues and future prospects). Cambridge: Cambridge University Press.

GRINEVALD, C. (1998). "Language endangerment in South America: a programmatic approach". In GRENOBLE, L. A. \& WHALEY, L. I. (eds.) Endangered languages. Language loss and community response (currents issues and future prospects). Cambridge: Cambridge University Press, pp. 124-159.

GROSJEAN, F. (1982). Life with two languages: an introduction to bilingualism. Cambridge: Harvard University Press.

GUEDES, M. (1991). Subsídios para uma análise fonológica do Mbyá. Campinas: Editora da Unicamp. (Série Línguas Indígenas).

HARRISON, C. (1974). Relatório Avá-Canoeiro. Brasília: SIL. (Arquivo Linguiístico nº 020).

HIMMELMANN, N. P. (1998). "Documentary and Descriptive Linguistics". Linguistics 36,. pp. 161-195.

Insetos.(1999). Guia prático. São Paulo: Nobel, 1999.

IPA. (1999). Handbook of The International Phonetic Association. Cambridge: Cambridge University Press.

JENSEN, C. J. S. (1989). O desenvolvimento histórico da língua Wayampi. Campinas: Editora da Unicamp. (Série Línguas Indígenas).

KIBRIK, A. E. (1977). The methodology of field investigation in Linguistics. Paris, Mouton.

LEITÃO, R. M. (2002). Relatório das atividades realizadas na área Avá-Canoeiro $n^{\circ} 4$. Goiânia: UFG/MA

LEITE, Y. (1995). "Estrutura silábica e articulação secundária em Tapirapé”. In WETZELS, L. (org.) Estudos fonológicos das línguas indígenas brasileiras. Rio de Janeiro: Editora da UFRJ. pp. 151-194.

(1977). Aspectos da fonologia e morfofonologia Tapirapé. Rio de Janeiro: Universidade Federal do Rio de Janeiro/Museu Nacional.

LEMOS BARBOSA, Pe. A. (1955). Pequeno vocabulário Tupi-Português. Rio de Janeiro: Livraria São José.

MARTINS, M. F. (1996). Incorporação nominal em Guarani Mbyá. Florianópolis: Universidade Federal de Santa Catarina. (Dissertação de Mestrado).

MEECH, D. (1961). Canoeiro Word List (Canoeiro-Tupi-Guarani). Brasília: SIL. p. 04.

MITHUN, M. (2001). "Who shapes the Record: the speaker and the linguist". In NEWMAN, P. \& RATLIFF, M. Linguistic Fieldwork. Cambridge: Cambridge University Press. pp. 34-54.

MONSERRAT, R. M. F. \& IRMÃZINHAS DE JESUS. (1998). Língua Asurini do Xingu. Observações gramaticais. CIMI/Prelazia do Xingu: Altamira. 
NEVES, M. H. M. (1999). (org.) Gramática do português falado. Volume VII: Novos Estudos. São Paulo: Humanitas/FFLCH/USP; Campinas: Editora da Unicamp.

NEWMAN, P. \& RATLIFF, M. (2001). Linguistic fieldwork. Cambridge: Cambridge University Press.

PAIVA, A. M. (1996). Elementos de fonologia Avá-Canoeiro. Goiânia: Universidade Federal de Goiás. (Dissertação de Mestrado).

PALACIN, L. (1994). O século do ouro em Goiás (1722-1822): estrutura e conjuntura numa Capitania de Minas. $4^{\mathrm{a}}$ ed. Goiânia: CEGRAF/Editora da UFG.

PEDROSO, D. M. R. (1994). O Povo Invisivel: a história dos Avá-Canoeiros nos séculos XVIII e XIX. Goiânia: Editora da UCG/FURNAS Centrais Elétricas As.

PEDROSO, D. M. R. (1992). Avá-Canoeiro: a história do Povo Invisível - séculos XVIII e XIX. Goiânia:

POHL, J. E. (1976). Viagem no interior do Brasil. Belo Horizonte: Itatiaia/ São Paulo: Editora da USP.

ROCHA, L. M. (1998). O Estado e os índios: Goiás 1850-1889. Goiânia: Editora da UFG.

RODRIGUES, A. D (2000). "Panorama das línguas indígenas da Amazônia". In QUEIXALÓS, F. \& RENAULT-LESCURE, O. (orgs.). As línguas amazônicas hoje. São Paulo: Instituto Socioambiental (ISA)/IRD/MPEG. pp.15-28.

.(1993). Endangered languages in Brazil. Symposium on Endangered Languages of South America. Rijks Universiteit Leiden.

.(1986). Línguas brasileiras. Para o conhecimento das línguas indígenas. São Paulo: Loyola. .(1984/1985). "Relações internas na família lingüística Tupi-Guarani". Revista Brasileira de Antropologia. Volumes XXVII/XXVIII. São Paulo: USP, pp. 33-53.

ROMAINE, S. (1995). Bilingualism. Oxford: Blackwell.

SAMARIN, W. J. (1967). Field Linguistics. A guide to Linguistic fieldwork. New York: Holt, Rinehart \& Winston.

SEKI, L. Gramática do Kamaiurá. Língua Tupi-Guarani do Alto Xingu. Campinas: Editora da Unicamp; São Paulo: Imprensa Oficial, 2000.

.(1984). "Problemas no estudo de uma língua em extinção". Boletim da Associação Brasileira de Lingüística. Campinas: Unicamp. Volume 6. pp. 109-118.

TORAL, A. A. de. (1984/1985). "Os índios negros ou os Carijó de Goiás: a história dos Avá-Canoeiro". Revista de Antropologia. Volumes XXVII/XXVIII. São Paulo: USP. pp. 287-325 pp.

.Vocabulário Avá-Canoeiro. s/d. (mimeo).

TOSTA, L. T. D. (1997). "Homi matou papai meu”: uma situação histórica dos Avá-Canoeiro. Brasília: UNB. (Monografia de Final de Curso).

VAUX, B. \& COOPER, J. (1999). Introduction to Linguistic Field Methods. LINCOM EUROPA. 